\title{
Measuring, Visualizing, and Controlling Intangible Assets in Knowledge Management
}

\author{
Bernhard F. Seyr ${ }^{1}$ (D) Thomas Hoffer $^{2}$
}

Received: 3 August 2019 / Accepted: 21 July 2020 /Published online: 5 August 2020

(C) The Author(s) 2020

\begin{abstract}
This article focuses on the advancement of common tools in the field of measurement, visualization, and controlling of intangible assets. In this course, the fundamentals are the Boston Matrix, the McKinsey Portfolio, the life cycle analysis, and the SWOT analysis. The authors apply a hermeneutical and conceptual approach based on a literature review in order to design new instruments for portfolio analyses of intangible assets. The newly adapted tools are examined with respect to their adequacy for the strategic evaluation and development of knowledge bases in organizations. The authors introduce a Knowledge Matrix linked to a life cycle model of knowledge. Furthermore, the SWOT analysis is adjusted for the use in strategic knowledge management. The results of this paper shall be the groundwork for the implementation and evaluation of such tools in practice.
\end{abstract}

Keywords Strategic knowledge management $\cdot$ Portfolio analysis $\cdot$ Strategic management . Evaluation · Organizational learning

\section{Introduction}

Knowledge management (KM) has become established as a multidisciplinary field of research in social sciences and management studies since the turn of the new millennium. Numerous scientific publications underpin the importance of KM. In this sense, $\mathrm{KM}$ is able to improve productivity and sustainability of organizations (Zheng and Wang 2018, 110-111). Furthermore, successful KM leads to competitive advantage

Bernhard F. Seyr

bernhard.seyr@uni-sopron.hu

Thomas Hoffer

1719001135@fh-burgenland.at

1 University of Sopron, Erzsébet ut. 9, H-9400 Sopron, Hungary

2 FH Burgenland, Campus Eisenstadt, Campus 1, A-7000 Eisenstadt, Austria 
(Tang et al., 2010; Gammelgaard and Ritter, 2005) in a fast-changing global business environment (Santoro et al., 2019). In contrast to the optimistic view of the academic literature, $\mathrm{KM}$ is often reduced to the level of information and communication technologies (especially databases), which is not appropriate for its multilayered nature regarding the dimensions man - organization - technology (Brandt and Massing 2002, 235-249). The practical application of a holistic understanding of KM (which is basically efficient and effective at the same time) is often neglected (Seyr 2015). In addition to such neglection, Tang et al. (2010) and Gammelgaard and Ritter (2005) only focus on efficiency, while Ferraris et al. (2017) concluded the importance of an efficient and effective use of knowledge. Therefore, KM is unable to unfold its full potential and it achieves only marginal effects. Technology should only be seen as a (necessary) tool to enable the processes of KM, but it should not replace KM itself (Sharma and Deb 2019, 763).

In order to implement sustainability within information management and KM, Erek and Zarnekow $(2009$, 424) introduce a regulator circuit containing the following phases: identification of resources, evaluation of resources, identification of measures, prioritization, implementation, action, and controlling (Fig. 1). The second and last phases (shaded grey in the graph) emphasize the importance of evaluation tools in the field of information management and KM.

Such evaluation tools are the main focus of this article, which is structured as follows: First, the authors review the most relevant research articles in the field of KM. The focus is on conceptual and practical studies to serve both the academic and the business environments. Second, the portfolio analyses are introduced in the context of KM. Third, the research methodology of the authors is explained. Fourth, different

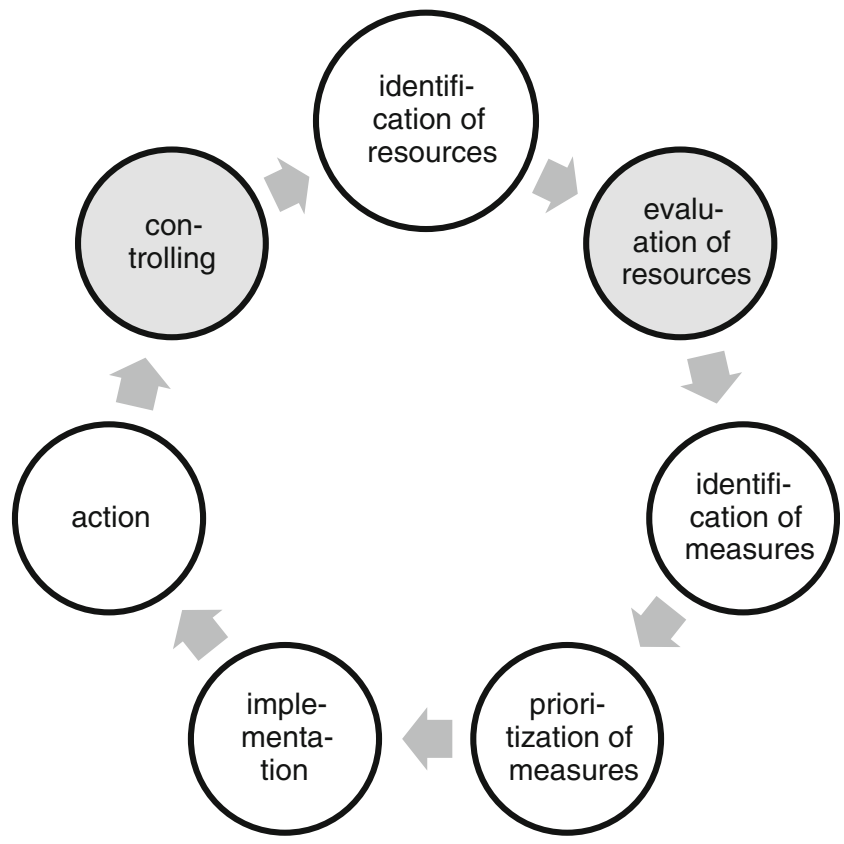

Fig. 1 Regulator circuit for information and knowledge management (own graph, inspired by Erek and Zarnekow 2009) 
approaches (Boston Matrix, the McKinsey Portfolio, the life cycle analysis, and the SWOT analysis) are described and adapted for use in strategic KM. Fifth, the adaptations are discussed, practical implications are given, conclusions are drawn about the academic contribution and practical use, and finally, an outlook for further research concludes this paper. Even if this work is of a conceptual nature, it is very important in the field of KM not only from a theoretical perspective but also in a practical sense. The tools adapted are very well known and build a theoretical foundation. The practical use of the approaches described and recommended needs to be further tested. One of the most significant gaps in the field is being addressed, and a solution provided, by introducing the different approaches in a strategic KM context: previous literature focuses on efficiency and neglects effectiveness, which does not make any approach strategic at all. Furthermore, the authors' recommended approach in KM is sustainable from the economic perspective of a firm. This fact does not only make the contribution relevant in theory but also helps firms to increase/optimize profits, and therefore the research is practically important.

\section{Literature Review}

The literature in the field of knowledge in a business context in the early $2000 \mathrm{~s}$ addressed fragmentation, overload and retrieval problems of knowledge and respectively management (Gammelgaard and Ritter, 2005), use, storage and accessibility of personal knowledge (Hicks et al., 2007), and other managerial approaches for a better understanding (e.g., Mathew and Kavitha, 2009).

Gammelgaard and Ritter (2005) addressed the fragmentation, overload, and retrieval problems of knowledge and the associated impact on its management. One possible practical solution is the development of virtual communities for overcoming these problems. Virtual communities shall be understood as "a group of frequently interacting individuals sharing a practice [...] taking place in cyberspace through information technology" (Gammelgaard and Ritter, 2005, 138). Most importantly, the authors found that these communities overcome the lack of knowledge context through communication with respective knowledge senders. The communication context was also addressed by Hicks et al. (2007), who extended the well-known 3-level transformation Knowledge Hierarchy, in which it is assumed that data are transformed into information. Then, information is networked and results in knowledge, or "information that becomes actionable is knowledge" (Hicks et al. 2007, n. p.). Not only for logical reasons but also for a paradigm shift in management theory, this hierarchy has been extended from a bottom-up only approach to bottom-up and top-down, because, of course, knowledge is needed to be able to create information and data in the first place. Hicks et al. (2007) point out that the Knowledge Hierarchy was helpful regarding codified knowledge, but not helpful in KM due to personal knowledge, which is part of KM. Hicks et al. (2006) defined personal (individual) knowledge as "knowledge contained only in the mind of a person." Personal (individual) knowledge can be graphically presented in a Knowledge Map. Such tools help to gain some insight into how and where knowledge is located in order to manage it in the future. Mathew and Kavitha (2009, n. p.) "highlighted certain steps for Knowledge Management Mapping leading to a more effective implementation in the Knowledge Management process." 
Moreover, Santoro et al. $(2019,1)$ investigated and assessed "how knowledge management and dynamic capabilities influence ambidextrous entrepreneurial intensity and firm performance." It was concluded that an ambidextrous firm is entrepreneurial, exploiting old, and exploring new knowledge. Furthermore, it develops incremental and radical products not only for a defined (home) market but also expands into new markets (abroad). From the managerial point of view, it was clearly pointed out that recognizing "exploration opportunities in adapting to the external environment" plays a significant role in today's globalized economy characterized by shortened product life cycles.

More recent research streams, from 2010 to the present day, focus in much more detail on practical solutions using theoretical foundations; in particular, the research conducted by Tang et al. (2010) is of the highest practical importance. It deals with the management of engineers' knowledge and consequently inefficiency in this area of management. As one solution to become more efficient, the authors introduce methods and procedures based on the Design Structure Matrix (DSM). The main objective of the DSM is the formalization of documentation and storing of knowledge. The authors point out that an improved understanding of "design routes and design history by linking designed items to rationales, decisions, and assumptions behind them" is a result of the successful documentation and storage of knowledge (Tang et al. 2010, 166).

Nonetheless, better understanding of how individual knowledge is being used within an organization is accompanied by the question of how structures within such an organization support (or impede) the management of knowledge. Vrontis et al., 2017, n. p.) researched the relationship "between organizational ambidexterity and firm performance, in terms of exploitation and exploration, for KIFs (Knowledge Intensive Firms)." It was concluded that the involvement of external knowledge had positive effects on the firm's performance. Additionally, it has been confirmed that external knowledge was "a mediator of the relationship between organizational ambidexterity and firm performance" (Vrontis et al., 2017 n. p.). Other research supports the general idea of cooperation between organizations. Ferraris et al. (2017) investigated the phenomena of firms opening their R\&D structure for external partners. They comprehended "the effect of the adoption of KM practices on the relationship between external sources of knowledge and MNC subsidiaries' innovation performance" (Ferraris et al., 2017, n. p.). It was concluded that firms are constantly investing in potential innovations to increase their competitiveness in markets. These efforts are not only made solely internally but also directed towards external sources of knowledge. It was further pointed out that headquarters must allocate appropriate funds and managerial resources to the subsidiary level for a successful (efficient and effective) use of knowledge. In addition to this study, Santoro et al. $(2018,2)$ investigated "whether formal and informal collaboration modes with Cultural and Creative Industries affect innovation performance moderated by Heterogeneous Sources of Knowledge." Such research is of great importance since networking, alliances, and inter-organizational cooperation have not only got the attention of scholars in the field of management studies in recent years but also are of great practical importance due to the ongoing process of globalization of economies. The results generally indicate that firms benefit from informal, but not from formal collaboration modes, and that a firm's knowledge base should be heterogeneous for a better understanding of relevant external sources of 
knowledge (Santoro et al., 2018, 6). Consequently, from a managerial point of view, networking is improving the ability to be innovative.

From the managerial perspective, important research was conducted by Ferraris et al. (2018, n. p.), exploring "the dual embeddedness of subsidiaries involved in the knowledge transfer process within multinational corporations' network." The authors found that internal embeddedness directly and positively influenced knowledge transfer; on the other hand, external embeddedness did not. Furthermore, the authors stressed the importance of allocating appropriate funds and managerial resources to the subsidiary level for developing internal and external embeddedness on high levels.

It is possible to summarize that the involvement of external knowledge in internal R\&D processes has been observed in different studies (e.g., Ferraris et al., 2017; Vrontis et al., 2017). Furthermore, the successful management of knowledge leads to competitive advantage (Tang et al., 2010; Gammelgaard and Ritter, 2005) in a fastchanging global business environment (Santoro et al., 2019). Additionally, the efficient management of knowledge seems to be not only of great scholarly interest but also of great practical use and managerial interest (Tang et al., 2010; Gammelgaard and Ritter, 2005). It must be critically underlined that Tang et al. (2010) and Gammelgaard and Ritter (2005) only focused on efficiency, but Ferraris et al. (2017) concluded the importance of an efficient and effective use of knowledge, which makes it a more strategic approach.

\section{Existing Approaches of Portfolio Analysis in Strategic KM}

An alternative portfolio for strategic KM was introduced by Probst, Raub, and Romhardt (2006, 51). This portfolio also aims to offer generic strategies for knowledge managers but it differs from the above-mentioned Knowledge Matrix in its fundamental design: Probst, Raub, and Romhardt $(2006,51)$ measure on the $x$-axis the use of knowledge and on the $y$-axis the knowledge advance. Therefore, the interpretation of the quadrants is also different. If both variables are low, the generic strategy is "outsourcing" as the knowledge has no high value for the organization. In situations with a low use of knowledge but a high knowledge advance, the strategic conclusion suggests the stronger application of the unused skills in order to improve the competitive position. With a strong use of knowledge but a low knowledge advance, the knowledge base should be upgraded. This competence should be enhanced due to its importance for the organization. If both use of knowledge and knowledge advance are high, the leverage effect should be exploited in order to transfer the knowledge to new products and markets.

Another portfolio model for the evaluation of resources was designed by Grant (2005, 477-479). It shows on the $x$-axis the importance of the organization's resource for the competitive situation and on the $y$-axis the external effects of the resource. External effects are seen as ecological and social aspects. If both factors are low, the generic strategy is "keep it running" which implies no further investments in this resource. If both factors are high, the future potential is also valued as high. That makes further investments necessary. For resources in the middle field, a selective strategy is recommended.

The technology portfolio which has been introduced by Baum, Coenenberg, and Guenther $(2013,265-267)$ is similar to the McKinsey Portfolio because it displays the 
strength of the resource on the $x$-axis and the attractiveness of the resource on the $y$ axis. The generic strategies also correspond to the McKinsey Portfolio (that means a divestment, selection, or investment strategy regarding the analyzed technology).

\section{Research Goals and Methodology}

This article aims to help expand KM in organizations beyond the technological level and enable a critical evaluation of the organizational knowledge base. Moreover, such evaluation tools shall facilitate strategic KM. In the KM model of Probst, Raub, and Romhard (2006, 58), the critical evaluation of knowledge is integrated into the following modules: assessment of knowledge, identification of knowledge (according to the knowledge targets), and knowledge development (following the acquisition of knowledge).

This goal should be reached by the adaption of well-known methods of portfolio analysis such as the Boston Matrix, the McKinsey Portfolio, the life cycle analysis, and the SWOT analysis for strategic KM. In this way, it is made possible to visualize existing knowledge bases in a "cockpit system" in order to establish a clearly-laid-out basis for decision making in strategic (knowledge) management. Moreover, the portfolio analysis enables a meta-view on existing knowledge bases. Thus, KM can be more efficient and effective in contributing to the organization's success. The establishment of a powerful reporting system in KM can also build the basis for an internal and external benchmarking of intangible assets (Catalfo 2015, 642). In this sense, academic literature emphasizes the importance of the close cooperation between controlling and strategy. Connected to this fact, the performance measurement of KM strategies is crucial for an organization's future (Weber, Schaeffer, Goretzki, and Strauß 2012, 34-35).

Botthof $(2012,83-90)$ illustrates in his paper the high importance of reporting tools that must be clearly structured, forward-looking, and standardized. In line with these criteria, this paper introduces some newly adapted controlling tools for strategic KM.

Summing up the main goal of this paper is the adaption of existing strategic controlling tools to the needs of strategic KM in measuring, visualizing, and controlling intangible assets in organizations.

The methodology is not empirical but creative, hermeneutical, conceptual, and explorative. Findings of the current literature are building the bases.

\section{Result: New Applications of Portfolio Analysis in Strategic KM}

\section{General Remarks}

Traditional instruments of portfolio analysis in strategic management are usually based on the factors of market and/or product with regard to marketing. For instance, the Boston Matrix has on its $x$-axis the relative market share and on its $y$-axis the market growth rate. Similar to this concept is the McKinsey Portfolio that allows general strategic conclusions like divest/harvest, protect/select, or invest/expand depending on the competitive strength and the market attractiveness associated with products or 
strategic business units. The life cycle analysis is connected to products and markets and illustrates the development of sales during a certain period of time.

In contrast to these instruments, the SWOT analysis can be seen as a tool for the internal and external organization analysis that can be easily adapted to the needs of strategic KM. Nonetheless, the term strategy needs a clear meaning and therefore a definition: In this paper, the meaning of strategy is derived from the Greek term "strategos." It was mainly used in military theory introduced by Von Clausewitz (1832); it was described as "the use of fights for the purpose of war." The term became popular in the first half of the twentieth century in American universities in the course area "Business Policy" (Hungenberg 2014) and was finally established in the science of business management at the beginning of the 1970s. In this period, the understanding emerged that it is a general direction (guidance) of a company's development, the longterm success, and internal and external appearance (positioning) of a company (Hungenberg 2014). Strategic objectives are parts of the company's vision, and short- and middle-term objectives are the (intended) outcomes of a strategic plan (Drummond et al., 2008), gauging the progress towards a company's vision (Ferrell and Hartline 2011).

As the above-mentioned tools of the portfolio analysis are well known for more than half a century, the authors may omit their detailed discussion. In fact, this paper discusses a new adaption of these tools according to the characteristics and needs of strategic KM in detail.

As the focus is not set on marketing, KM tools do not directly refer to the factors market and product. In contrast to marketing, KM has to provide informational bases for processes in organizations in a wider perspective. The factors environment (especially the stakeholders of the organization like competitors and customers) and contents of knowledge (as products of KM) can be seen as important points of origin in this paper.

Appropriate controlling tools of strategic KM are essential to ensure the organization's ability to react, coordinate, learn, and innovate in order to survive in a dynamic environment (Gueldenberg 2001, 318).

Taking these facts into consideration, the newly introduced portfolios and tools in this paper are based on the preceding conceptual work of Bernhard F. Seyr at the University of Sopron.

\section{The Knowledge Advance and Growth of Importance Portfolio (Knowledge Matrix)}

The Boston Matrix (the Boston I portfolio) as well as the McKinsey Portfolio (Baum, Coenenberg and Guenther 2013, 224-230; Thommen and Achleitner 2009, 10211023; Baum, Coenenberg and Guenther 2013, 230-237) serve as bases for the Knowledge Advance and Growth of Importance Portfolio by combining and adapting them to the needs of KM.

The Boston Matrix categorizes strategic business units or products, according to their relative market share and the market growth rate, into one of four quadrants.

The Poor Dogs have a low market share and a low market growth. The recommended generic strategy in this field is "divest." The Question Marks are those with a low market share but a high market growth. They should be monitored and carefully developed. The Stars have a high market share and a high market growth. On the one 
hand, they generate high turnover; on the other hand, they consume their cash flows due to their expansion costs. The Stars should be treated as the basis for the current and future success. In contrast, the Cash Cows are distinguished by a high market share but a low market growth. They generate positive cash flows and should serve as long as possible. The generic strategy in this case is "harvest."

The McKinsey Portfolio also analyzes products or business units. The $x$-axis shows the competitive strength of a product or a business unit. Its $y$-axis demonstrates the attractiveness of an industry. The McKinsey Portfolio consists of nine fields and can be seen as an enhancement of the Boston Matrix. From the McKinsey Portfolio can be deduced three general recommendations:

1. If the competitive strength is low as well as the industry attractiveness, or one factor is low and the other is medium, a divesting strategy should be appliedsimilar to the Poor Dogs.

2. With high competitive advantages in a field or high industry attractiveness, a selective strategy should be implemented. This can be realized by improving the market position (offensive strategy) or by a defensive strategy in order to avoid further deterioration. A selective strategy can also be used as a transition strategy between a divestment and an expansion strategy.

3. For medium positions of a certain factor combined with a high value of the other factor, or with high values of both factors, the generic strategy should be "expand" in order to generate growth for the price of investments.

In the course of the adaption of these portfolios for KM, the axes have to be modified. Knowledge has no measurable relative market share like a product or a strategic business unit (see the Boston Matrix). Therefore, the factor "relative market share" is replaced by "relative knowledge advance." In this sense, the variable on the $x$-axis is similar to the McKinsey Portfolio that shows the competitive strength on this axis. The relative knowledge advance is understood in a certain area of knowledge or skills in comparison with the competitors. The knowledge advance can also be negative if the analyzed organization has a competitive disadvantage in a certain area.

The market growth rate of the Boston Matrix (on the $y$-axis) is replaced by "growth of importance" in the Knowledge Matrix in this paper. The growth of importance shows whether the analyzed knowledge field of the organization will gain more interest in future or not. Here also the factor can be negative if the knowledge field is losing importance. In some aspects, this value corresponds with the industry attractiveness in the McKinsey Portfolio.

Instead of strategic business units (or products), the Knowledge Matrix (Fig. 2) displays strategic fields of the organization's knowledge by circles. It is possible to show the volume of investment in these fields by the radius. Figure 2 can be interpreted in this sense: Strategic Fields A and B reveal a relatively low consumption of investments in contrast to Strategic Field C, which lies between Diamonds and Work Horses.

This form of graph conforms to the principles of the portfolio technique where the importance of the strategic business units (the sales and associated turnover) corresponds to the radius of their respective circles. Also, in the usual sense of the portfolio analysis, the $x$-axis shows the organization's dimension and the $y$-axis displays the environmental dimension (Baum, Coenenberg, and Guenther 2013, 223). 


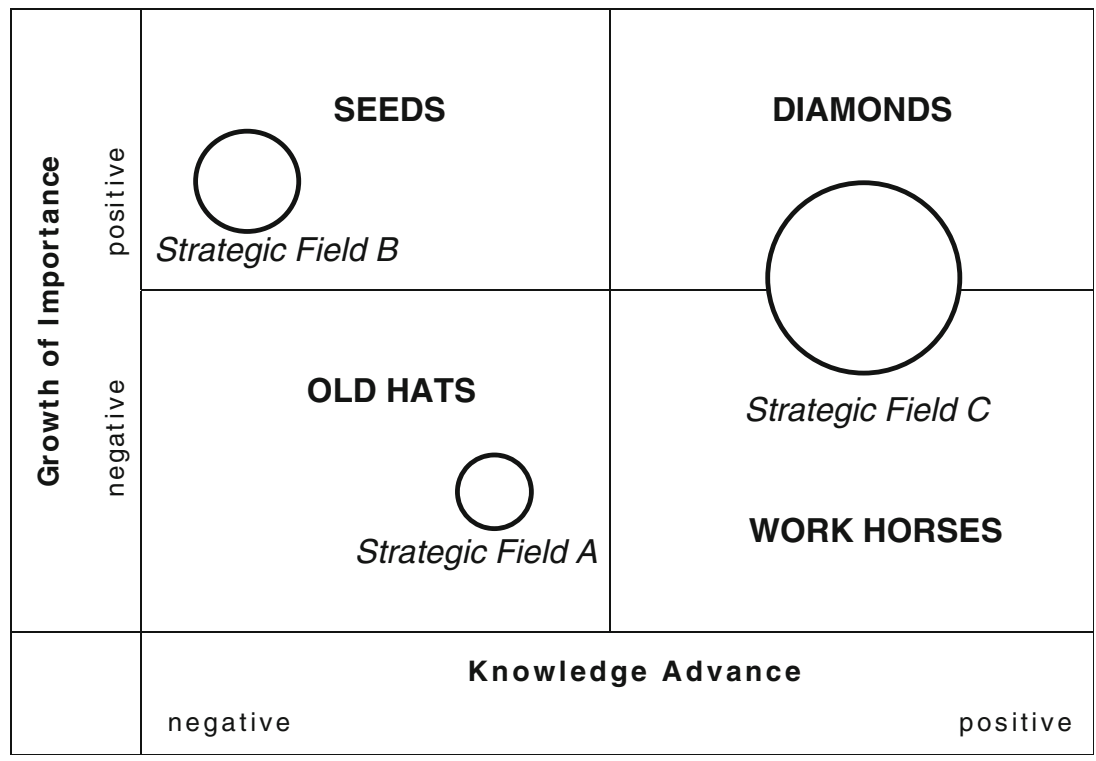

Fig. 2 The Knowledge Matrix (own concept and graph)

For the allocation of the different items (strategic areas of knowledge) within the portfolio, internal and external analytical and empirical studies can be used. Moreover, market surveys, expert interviews, and experts and practitioners' experience may help to estimate the positions. The restriction of the portfolio may lie in the difficulty to determine exact positions on the axes - but this methodological problem is comparable with other portfolio tools where factors like "industry attractiveness" also cannot be exactly determined. In spite of this, the portfolio technique provides a first overview in order to facilitate strategic decisions.

The value of the Knowledge Matrix lies in the evaluation of knowledge bases regarding long-term oriented KM. During the evaluation or specification of the knowledge and information strategies, generic strategies shorten the decision processes (Heinrich and Stelzer 2011, 117). In this context, a restriction of the portfolio technique can be seen in the reduction of the complex reality to only two attributes in the case of a two-dimensional portfolio.

From the Knowledge Matrix, the following generic strategies can be deduced:

Old Hats These knowledge bases are not important for the future success of the organization. Moreover, the organization has no relevant strengths in this area of knowledge. Thus, these areas should not be fostered in future. No additional investments should be made. These knowledge bases are disposable resources that should be sold, outsourced, or given up (Johnson and Scholes 1999, 153-155).

Seeds These knowledge bases should be cultivated and carefully watched. Investments make sense because an increase regarding the strategic importance of the seeds can be expected but the organization has no actual knowledge advances in this area at the time. Seeds belong to "innovative knowledge" (Maier 2004, 99) and should be developed to Diamonds. 
Diamonds These are distinguished by outstanding competences in the associated area as well as a high growth of importance. Diamonds are current and future core competences of an organization. Further investments are recommended in order to strengthen these future critical factors of success. Diamonds belong to the core resources building competitive advantages and ensuring a sustainable organizational profile (Johnson and Scholes 1999, 153-155).

Work Horses Work Horses are important knowledge bases that keep the organization running without having a future potential. They consist of necessary basic knowledge and skills to run a business according to the state of the art. Work Horses should be maintained without sacrificing resources for long-term investments. Work Horses do not possess the potential for improving the organization's competitive position (Johnson and Scholes 1999, 153-155). In a mid- or long-term view, Work Horses may develop into Old Hats.

\section{Life Cycle Analysis}

$\mathrm{KM}$ is especially important for the success of companies with short product life cycles (Disterer 2007, 170). In close connection with the newly introduced Knowledge Matrix and the Boston Matrix stands the life cycle model. Within the wellknown model of the product life cycle (Baum, Coenenberg, and Guenther 2013, 225-228), the product life is displayed within idealized, predefined phases in its lifespan by a graph - usually showing the generated turnover and profit. Upon application of this model in KM, no product is displayed by the graph, but a strategic, relevant field of knowledge in connection with its importance as a factor of success. The view can be from the perspective of the organization itself or from the whole industry sector. According to the life cycle model, the following typical phases (Fig. 3) are given in strategic KM:

Innovation The field of knowledge is relatively new and unknown. It is unclear whether the knowledge will gain importance as a success factor in future. Such knowledge areas regularly belong to the Seeds in the Knowledge Matrix.

Growth Knowledge bases in this phase gain more and more importance and attention and are growing rapidly. Such knowledge bases belong to the "Diamonds" in the Knowledge Matrix as they are meaningful for current and future success.

Maturity In this phase, the importance of the particular knowledge base reaches its peak. Knowledge bases in the maturity phase are part of the status quo, actually important but mostly known in the industry. Such knowledge capital corresponds to the "Work Horses" in the Knowledge Matrix. Everyday business relies on this knowledge but its innovative potential is low.

Degeneration This type of knowledge has become out of date with no visible future relevance. Knowledge in the degeneration phase belongs to the "Old Hats" in the Knowledge Matrix. 


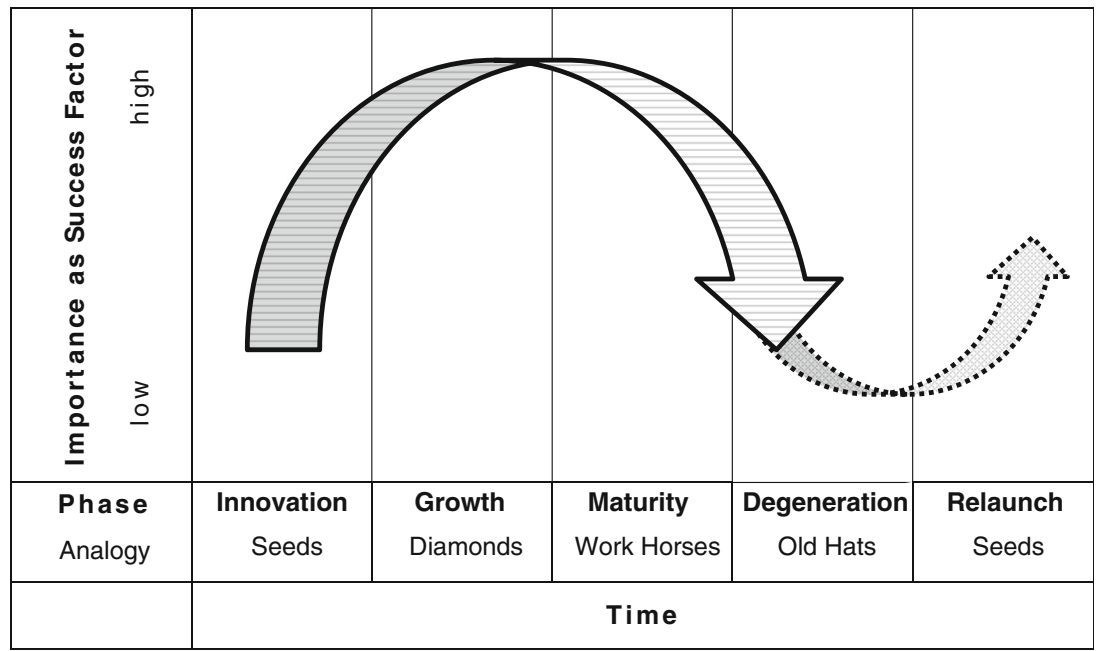

Fig. 3 Life cycle of knowledge (own concept and graph)

Relaunch Maybe old knowledge can be activated to solve new problems, newly combined or developed. In this case, a relaunch of such knowledge would be possible. Then its importance could grow again. In the Knowledge Matrix, such relaunched knowledge could be part of the "Seeds" again.

\section{SWOT Analysis}

The SWOT analysis (Kotler, Berger, and Rickhoff, 2010, S. 30) is based on strengths, weaknesses, opportunities, and threats. It is an instrument for strategic planning (Pongpimol et al., 2020, 204) regarding an organization or regarding single business units. Its internal analysis detects current strengths and weaknesses, and the external analysis refers to future opportunities and risks.

SWOT analysis can also be transferred into KM (Fig. 4):

Within the internal analysis of KM, strengths are units where the organization can take advantage of core competences or deep knowledge. In contrast, weaknesses are

\begin{tabular}{|l|c|c|}
\hline Internal Analysis & Strengths & Knowledge gaps \\
\hline External Analysis & Core competences & Thportunities \\
\hline
\end{tabular}

Fig. 4 SWOT analysis in knowledge management (own concept and graph) 
units where the organization has no deeper knowledge or strategic knowledge advances compared with its rivals.

It must be pointed out that any isolated view within the internal level of analysis may lead to wrong conclusions, because there are also external issues which are not directly controllable by the firm itself. These non-influenceable variables may include macro-economical, political, and legal aspects (Bruhn, 2001), and they build a fundamental basis for strategic planning (Meffert et al., 2015). The external analysis regarding the environment of an organization can detect opportunities and threats. Opportunities can be created by changes in the environment that can be useful or positive for the organization. These can be positive political, economic, social, technological, ecological, or legal changes (see the PESTEL factors). For example, it can be an opportunity for a cardboard producer if disposable plastic products are banned and the cardboard producer can offer substitutes. In the Knowledge Matrix, knowledge about such substitutes can develop into Diamonds that are in their phase of growth within the product life cycle.

Threats are changes in the environment that may harm the organization. In this case, for a producer of disposable plastic products, the current legal development is a threat. Knowledge bases in the area of disposable plastic will not be a competitive advantage anymore and will belong to both the "Old Hats" in the Knowledge Matrix and to knowledge in the degeneration phase.

While a simple SWOT analysis only states/lists some recognizable strengths and weaknesses from an internal perspective and opportunities and threats from an external perspective, the Dynamic SWOT analysis combines these perspectives for developing a best-possible "fit" between the internal and external environment of a company (Poeschl, 2013). There are four types of possible strategic measures (Poeschl, 2013, 46):

Strengths and Opportunities (SO): Use strengths to take advantage of opportunities.

Strengths and Threats (ST): Use strengths to avoid threats.

Weaknesses and Opportunities (WO): Overcome weaknesses by taking advantage of opportunities.

Weaknesses and Threats (WT): Minimize weaknesses and avoid threats.

However, the development of respective strategies needs further consideration of the assumed stakeholder's support or opposition. The main objective shall be, following the assumptions Poeschl (2013) made, to minimize obstructive intentions from stakeholders by, for instance, involving the relevant parties in a company's strategy development process.

The strategic target of the combination of strengths and opportunities (SO) means, from the view of KM, that the organization takes advantage of opportunities that fit the core competences in order to fulfill a matching strategy, which is, by its nature, "aggressive" (Pongpimol et al., 2020, 216).

For WO combinations (weaknesses and opportunities), weaknesses shall be reduced and transformed into strengths by a transformation strategy which takes advantage of new opportunities. In terms of KM, this means that knowledge 
bases in areas with good prospects will be enlarged. This strategy can be considered to be turnaround oriented (Pongpimol et al., 2020, 216).

The neutralization, also diversification (Pongpimol et al., 2020, 216), strategy is recommended for ST combinations (strengths and threats). Strengths will be used to fight against threats. The organization can use its strong core competences in this case.

For WT combinations (weaknesses and threats), the most adverse combinations, a defensive strategy (Pongpimol et al., 2020, 216) is recommended. From the perspective of $\mathrm{KM}$, these are circumstances where little or no expertise is available within the organization but there are massive threats in this field at the same time. In the example of the producer of disposable plastic articles, this means no knowledge about ecofriendly materials in the event of a plastic ban. A defense strategy could be to try to sell the plastic products in regions where it is still allowed or to exploit legal loopholes.

\section{Discussion: Implications, Limitations, Conclusions, and Outlook}

In this article, portfolio analysis for strategic KM was applied, thereby facilitating a link between controlling and strategy, and creating a basis for internal and external benchmarking. Undoubtedly, such facilitation not only adds value to the relevant body of theoretical literature but also has great practical implications for organizations. In this context, the newly developed Knowledge Matrix displays the knowledge advance and the growth of importance. This matrix adapts the Boston Matrix and the McKinsey Portfolio to the needs of strategic KM. Such adaptations lead to a modern and interdisciplinary use of well-known models in a way that deviates from how the original models were intended to be used.

Undoubtedly, in the current business environment (also known as the globalized economy), classical tools such as the Boston Matrix and the McKinsey Portfolio are, as stand-alone tools, not very applicable. On the one hand, the Boston Matrix, one of the very first portfolio models (Burns, 2014, 23), is a very simple tool which is severely limited, and weaknesses can be clearly named, such as "its reliance on only two factors, ambiguity in measuring the factors, and confusion over the information provided by the model" (Burns, 2014, 24). On the other hand, there is the McKinsey Matrix, which was initially developed to address shortcomings of the Boston Matrix (Burns, 2014, 24).

However, the attempt resulted in "an increase of ambiguity and complexity of the model and add uncertainty to the determination of the correct elements to include" (Burns, 2014, 25). Nonetheless, the Knowledge Matrix, which is a hybrid of the Boston Matrix and the McKinsey Portfolio, can be used as a "cockpit system" for intangible assets and facilitates the evaluation of different knowledge bases. Moreover, the paper introduces applications of the portfolio technique in the management of technology, information, and knowledge based on a short literature review.

Additionally, the article combines the life cycle analysis with the portfolio analysis in KM to deduce strategic conclusions. Besides that, the application of the SWOT analysis is recommended in long-term oriented $\mathrm{KM}$ in order to detect strengths, weaknesses, opportunities, and threats linked with intangible assets. Thus, also, opportunities for success can consequently be pursued and risks can be minimized.

Future research shall be focused on testing and applying these tools in practice. From the practical perspective, it must be pointed out that the approaches explained 
must be applied dynamically and reflect the real environment of the firm. Realism is of particular importance in the SWOT analysis, and false pride or hubris will lead to wrong conclusions or implications costing the firm dearly.

Funding Information Open access funding provided by University of Sopron.

Open Access This article is licensed under a Creative Commons Attribution 4.0 International License, which permits use, sharing, adaptation, distribution and reproduction in any medium or format, as long as you give appropriate credit to the original author(s) and the source, provide a link to the Creative Commons licence, and indicate if changes were made. The images or other third party material in this article are included in the article's Creative Commons licence, unless indicated otherwise in a credit line to the material. If material is not included in the article's Creative Commons licence and your intended use is not permitted by statutory regulation or exceeds the permitted use, you will need to obtain permission directly from the copyright holder. To view a copy of this licence, visit http://creativecommons.org/licenses/by/4.0/.

\section{References}

Baum, H.-G., Coenenberg, A. G., \& Guenther, T. (2013). Strategisches controlling. Stuttgart: SchaefferPoeschel.

Botthof, H.-J. (2012). Die 12 haeufigsten Fehler im Reporting. In A. Klein (Ed.), Reporting und business intelligence (pp. 83-90). Freiburg: Haufe.

Brandt, P., \& Massing, M. (2002). Mensch - Organisation - Technik. Wissensmanagement in KMU. In R. Franken \& A. Gadatsch (Eds.), Integriertes Knowledge Management: Konzepte, Methoden, Instrumente und Fallbeispiele (pp. 235-249). Wiesbaden: Vieweg+Teubner.

Bruhn, M. (2001). Marketing: Grundlagen für Studium und Praxis (5th ed.). Wiesbaden: Gabler.

Burns, D. J. (2014). Succeeding at new businesses: a matrix to measure flexibility. Journal of Business Strategy, 35(5), 23-30.

Catalfo, P. (2015). Methodological accounting tools for the evaluation of intangibles management in research institutions: some empirical remarks. Journal of Service Science and Management, 8, 638-648. https://doi.org/10.4236/jssm.2015.84064.

Clausewitz, M. v. (ed). (1832-1834). Vom Kriege. Hinterlassenes Werk des Generals Carl von Clausewitz, Bd. 1-3. Berlin: Ferdinand Dümmler.

Disterer, G. (2007). Betriebliches Wissensmanagement. In C. Steinle \& A. Daum (Eds.), Controlling. Kompendium fuer Ausbildung und Praxis (pp. 169-189). Stuttgart: Schaeffer-Poeschel.

Drummond, G., Ensor, J., \& Ashford, R. (2008). Strategic marketing: planning and control. 3rd edition. Amsterdam: Butterworth-Heinemann.

Erek, K., \& Zarnekow, R. (2009). Managementansaetze fuer nachhaltiges Informationsmanagement. In F. Keuper \& F. Neumann (Eds.), Wissens- und Informationsmanagement. Strategien, Organisation, Prozesse (pp. 413-438). Wiesbaden: Gabler.

Ferraris, A., Santoro, G., \& Dezi, L. (2017). How MNC's subsidiaries may improve their innovative performance? The role of external sources and knowledge management capabilities. Journal of Knowledge Management, 21(3), 540-552.

Ferraris, A., Santoro, G., \& Scuotto, V. (2018). Dual relational embeddedness and knowledge transfer in European multinational corporations and subsidiaries. Journal of Knowledge Management.

Ferrell, O. C., \& Hartline, M. D. (2011). Marketing Strategy. 5th edition. Mason: South Western Cengage Learning.

Gammelgaard, J., \& Ritter, T. (2005). The knowledge retrieval matrix: codification and personification as separate strategies. Journal of Knowledge Management, 9(4), 133-143.

Gueldenberg, S. (2001). Wissensmanagement und Wissenscontrolling in lernenden Organisationen. Ein systemtheoretischer Ansatz. Wiesbaden: Springer.

Grant, R. M. (2005). Contemporary strategy analysis: concepts, techniques, applications. Oxford: Blackwell.

Heinrich, L. J., \& Stelzer, D. (2011). Informationsmanagement. Grundlagen, Aufgaben, Methoden. Muenchen: Oldenbourg. 
Hicks, R., Dattero, R., \& Galup, S. (2006). The five tier knowledge management hierarchy. Journal of Knowledge Management, 1(10), 19-31.

Hicks, R. C., Galup, S. D., \& Dattero, R. (2007). The transformations in the five tier knowledge management transformation matrix. Journal of Knowledge Management Practice, 8(1).

Hungenberg, H. (2014). Strategisches Management in Unternehmen - Ziele, Prozesse, Verfahren. 8th edition. Wiesbaden: Springer Fachmedien.

Johnson, G., \& Scholes, K. (1999). Exploring corporate strategy. London: Prentice Hall.

Kotler, P., Berger, R., \& Rickhoff, N. (2010). The quintessence of strategic management. Berlin: Springer.

Maier, R. (2004). Knowledge management systems. Information and communication technologies for knowledge management. Berlin: Springer.

Mathew, V., \& Kavitha, M. (2009). Implementing knowledge management knowledge mapping, matrix and supports. Journal of Knowledge Management Practice, 10(1).

Meffert, H., Bruhn, M., \& Hadwich, K. (2015). Dienstleistungsmarketing - Grundlagen, Konzepte, Methoden (8th ed.). Wiesbaden: Springer Fachmedien.

Poeschl, H. (2013). Strategische Unternehmensführung zwischen Shareholder-Value und Stakeholder-Value. Wiesbaden: Springer.

Pongpimol, S., Badir, Y., Erik, B., \& Sukhotu, V. (2020). A multi-criteria assessment of alternative sustainable solid waste management of flexible packaging. Management of Environmental Quality, 31(1), 201-222.

Probst, G., Raub, S., \& Romhardt, K. (2006). Wissen managen. Wie Unternehmen ihre wertvollste Ressource optimal nutzen. Wiesbaden: Springer Gabler.

Santoro, G., Bresciani, S., \& Papa, A. (2018). Collaborative modes with cultural and creative industries and innovation performance: the moderating role of heterogeneous sources of knowledge and absorptive capacity. Technovation.

Santoro, G., Thrassou, A., Bresciani, S., \& Del Giudice, M. (2019). Do knowledge management and dynamic capabilities affect ambidextrous entrepreneurial intensity and firms' performance? IEEE Transactions on Engineering Management, 1, 9.

Seyr, B. F. (2015). Die drei Dimensionen des Wissensmanagements: Empirische Studie anhand des 3-DModells zur Selbstevaluation von Organisationen. Journal of Economy \& Society, 2015(1-2), 3-27.

Sharma, V. K., \& Deb, M. (2019). Knowledge management through technology: exploring extant research using nVivo. Theoretical Economics Letters, 9, 761-770. https://doi.org/10.4236/tel.2019.94050.

Tang, D., Zhu, R., Tang, J., Xu, R., \& He, R. (2010). Product design knowledge management based on design structure matrix. Advanced Engineering Informatics, 24(2), 159-166.

Thommen, J.-P., \& Achleitner, A.-K. (2009). Allgemeine Betriebswirtschaftslehre. Umfassende Einfuehrung aus managementorientierter Sicht. Wiesbaden: Gabler.

Vrontis, D., Thrassou, A., Santoro, G., \& Papa, A. (2017). Ambidexterity, external knowledge and performance in knowledge-intensive firms. The Journal of Technology Transfer, 42(2), 374-388.

Weber, J., Schaeffer, U., Goretzki, L., \& Strauß, E. (2012). Die zehn Zukunftsthemen des Controllings. VILEY-VCH: Weinheim.

Zheng, J. B., \& Wang, Y. N. (2018). Research on knowledge resources investment decisions in cooperated new product development. Journal of Service Science and Management, 11, 101-115. https://doi. org/10.4236/jssm.2018.111010.

Publisher's Note Springer Nature remains neutral with regard to jurisdictional claims in published maps and institutional affiliations. 